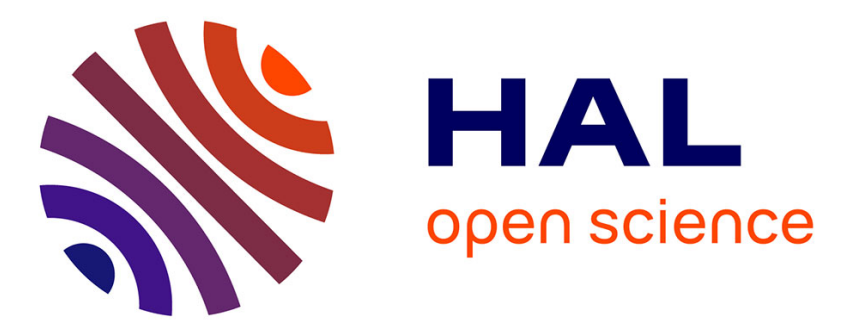

\title{
Crimean-Congo hemorrhagic fever serosurvey in at-risk professionals, Madagascar, 2008 and 2009
}

\author{
Soa Fy Andriamandimby, Philippe Marianneau, Jean-Théophile
}

Rafisandratantsoa, Pierre E. Rollin, Jean-Michel Heraud, Noël Tordo, Jean-Marc Reynes

\section{To cite this version:}

Soa Fy Andriamandimby, Philippe Marianneau, Jean-Théophile Rafisandratantsoa, Pierre E. Rollin, Jean-Michel Heraud, et al.. Crimean-Congo hemorrhagic fever serosurvey in at-risk professionals, Madagascar, 2008 and 2009. Journal of Clinical Virology, 2011, 52 (4), pp.370 - 372. 10.1016/j.jcv.2011.08.008 . pasteur-01665271

\section{HAL Id: pasteur-01665271 \\ https://hal-riip.archives-ouvertes.fr/pasteur-01665271}

Submitted on 15 Dec 2017

HAL is a multi-disciplinary open access archive for the deposit and dissemination of scientific research documents, whether they are published or not. The documents may come from teaching and research institutions in France or abroad, or from public or private research centers.
L'archive ouverte pluridisciplinaire HAL, est destinée au dépôt et à la diffusion de documents scientifiques de niveau recherche, publiés ou non, émanant des établissements d'enseignement et de recherche français ou étrangers, des laboratoires publics ou privés. 
Short communication

\title{
Crimean-Congo hemorrhagic fever serosurvey in at-risk professionals, Madagascar, 2008 and 2009
}

\author{
Soa Fy Andriamandimby ${ }^{a}$, , Philippe Marianneau ${ }^{\mathrm{b}}$, Jean-Théophile Rafisandratantsoa ${ }^{\mathrm{a}}$, Pierre E. Rollin ${ }^{\mathrm{c}}$, \\ Jean-Michel Heraud $^{a}$, Noël Tordo ${ }^{\mathrm{d}}$, Jean-Marc Reynes ${ }^{\mathrm{a}}$

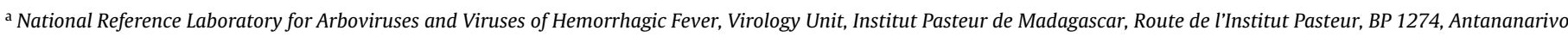 \\ 101, Madagascar \\ b OIE Reference Laboratory for RVFV and CCHFV, Agence Nationale de Sécurité Sanitaire, 31 Avenue Tony Garnier, 69394 Lyon Cedex 07, France

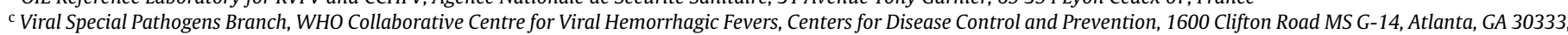 \\ USA

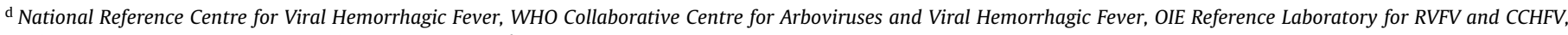 \\ Institut Pasteur, 21 Avenue Tony Garnier, 69365 Lyon Cedex 07, France
}

\section{A R T I C L E I N F O}

\section{Article history:}

Received 13 May 2011

Received in revised form 25 July 2011

Accepted 8 August 2011

\section{Keywords:}

Crimean-Congo hemorrhagic fever

Madagascar

Surveys

\begin{abstract}
A B S T R A C T
Background: Crimean-Congo hemorrhagic fever (CCHF) is a zoonotic arboviral infection with hemorrhagic manifestation and often a fatal ending. Human become infected mainly through tick bite or by crushing infected tick, by contact with blood or tissues from viraemic livestock or patient. CCHF virus (CCHFV) has been isolated once in Madagascar but data on the epidemiology of the disease in the country are very scarce.

Objectives: To investigate the circulation and the geographic distribution of CCHFV infection among at risk population in Madagascar.

Study design: A national cross-sectional serologic survey was performed in 2008-2009 among slaughterhouse workers.

Results: A total of 1995 workers were included. A recent CCHFV infection was detected in 1 of the 1995 participants $(0.5 \%$; $95 \%$ confidence interval $[\mathrm{CI}]$ : $0-0.15 \%)$, and a past CCHFV infection was detected in 15 participants $(0.75 \%$; $95 \% \mathrm{CI}: 0.37-1.13 \%)$.

Conclusion: Overall, the percentage of CCHFV infection seen in Madagascar among at-risk professionals is very low compared to endemic countries. An assessment of the prevalence in livestock as a sensitive indicator of CCHFV activity must be considered in order to confirm the lack or the weak endemicity of CCHF in Madagascar.
\end{abstract}

(c) 2011 Elsevier B.V. All rights reserved.

\section{Background}

Crimean-Congo hemorrhagic fever (CCHF) is a tick-borne disease caused by a virus (CCHFV) belonging to the family Bunyaviridae, genus Nairovirus (reviewed in 1,2). This zoonosis is largely distributed in Africa, Asia, Middle East and southern Europe (Balkan Peninsula). Hyalomma spp. is the most important and widely distributed tick vector, but other genera (Rhipicephalus, Boophilus, Dermacentor, and Ixodes) may have been contributed to CCHFV ecological cycle. Ruminants, but also small terrestrial mammals and birds are involved in an enzootic tick-vertebrate-

Abbreviations: CCHF, Crimean-Congo hemorrhagic fever; CCHFV, CrimeanCongo hemorrhagic fever virus; ELISA, enzyme-linked immunosorbent assay; CDC, Centers for Disease Control and Prevention.

* Corresponding author. Tel.: +261 2022412 72; fax: +261 202241534 .

E-mail address: soafy@pasteur.mg (S.F. Andriamandimby). tick cycle. Human become infected through tick bite or by crushing infected tick, by contact with blood or tissues from viraemic livestock, or by unprotected contact with biological fluids of a CCHF patient during the acute phase of infection. Disease is seen only in humans and frequently fatal with severe hemorrhagic signs. Treatment is symptomatic and to date, no vaccine is available. ${ }^{1,2}$

In Madagascar, CCHFV was isolated only once, from Rhipicephalus (Boophilus) microplus ticks collected on cattle, in March 1985, in the main slaughterhouse in Antananarivo. Animals were coming from Tsiroanomandidy, in the highlands, $150 \mathrm{~km}$ West from Antanananarivo. It was the largest live market in the country receiving cattle from all places in Madagascar. ${ }^{3}$

Phylogenetic studies based on partial $\mathrm{S}$ sequences indicated that the Malagasy strain was closer to strains isolated in MiddleEast and Asia than to African isolates. ${ }^{4}$ The only serological evidence of CCHFV human infection (using immunofluorescence assay) was demonstrated in 2 out of 149 individuals sampled in 1988 in Mandoto, a cattle breeding area in the highlands. ${ }^{5}$ 
Data on CCHF epidemiology in Madagascar are consequently very limited.

\section{Objectives}

To investigate the circulation and the geographical distribution of CCHFV infection among at risk population in Madagascar.

\section{Study design}

We performed a nationwide serological survey, from September 2008 through May 2009, among 1995 human volunteers at high risks of zoonotic infection as CCHF. ${ }^{6}$ These volunteers were people living in 106 out of 111 administrative districts of Madagascar and working in slaughterhouses, exposed to fresh meat or blood of livestock since at least 2007. The study was approved by the Malagasy National Ethical Committee. Informed written consent was obtained from the participants. Detection of IgM and IgG antibodies against CCHFV was performed by ELISA as previously described. ${ }^{7}$ Briefly, following heat and detergent inactivation, sera were tested by CCHFV-specific IgM and IgG ELISAs. The assays were completed using inactivated CCHFV-infected Vero E6 cell antigens and uninfected Vero E6 cell antigens, and using four dilutions of each serum $(1 / 100,1 / 400,1 / 1600,1 / 6400)$. Titers and the cumulative sum of optical densities of each dilution $\left(\mathrm{SUM}_{\mathrm{OD}}\right)$ minus the background absorbance of uninfected control Vero E6 cells (adjusted SUM $\mathrm{OD}_{\mathrm{OD}}$ ) were recorded. Results of the assays for sera were considered positive only if the adjusted $S U M_{O D}$ and titer were above preestablished conservative cutoff values, which were set for IgM ELISA $(\geq 0.75$ and $\geq 1 / 400$ ) and IgG ELISA ( $\geq 0.95$ and $\geq 1 / 400$ ). Positive samples and $3 \%$ of the negative samples tested in the Institut Pasteur in Madagascar (IPM) were sent to the Institut Pasteur in Lyon and to the CDC in Atlanta to validate the IPM ELISA results.

\section{Results}

A total of 1995 persons, aged 15-85 years participate to the study. The median age was 34 years (36 missing data). The sex ratio was 13.7 (six missing data). A recent CCHFV infection (presence of IgM against CCHFV and lack of IgG against CCHFV) was detected in 1 of the 1995 participants $(0.5 \%$; $95 \%$ confidence interval $[\mathrm{CI}]: 0-0.15 \%$ ), and a past CCHFV infection (presence of IgG against CCHFV and lack of IgM against CCHFV) was detected in 15 participants $(0.75 \%$; $95 \%$ CI: $0.37-1.13 \%)$. Titers were 400,1600 , and 6400 for 11,3 and 1 participants, respectively. CCHFV antibody positive subjects were detected in 14 of the 106 districts tested suggesting a scattered distribution (Fig. 1). The seropositivity was not significantly found associated with age, sex or location of activity of participants (data not shown).

\section{Discussion}

Overall, the percentage of CCHFV infection seen in Madagascar among at-risk professionals is very low compared to those observed in endemic countries like Mauritania (7\%) and United Arab Emirates (6\%). ${ }^{7,8}$ This observation may be explained by the lack of ticks of the genera Hyalomma in Madagascar. ${ }^{9}$ Rhipicephalus (Boophilus) microplus, the species found infected by CCHFV in Madagascar is widely distributed in the country up to $1950 \mathrm{~m}$ of altitude (Stachurski, pers. comm.). However, the vector competence of this species has not been demonstrated in the laboratory. ${ }^{2}$

The low percentage of detection of human antibodies against CCHFV and the scattered geographic distribution may be the consequence of repeated introductions of infected animals, large movements of domestic ruminants in the country, and abortive

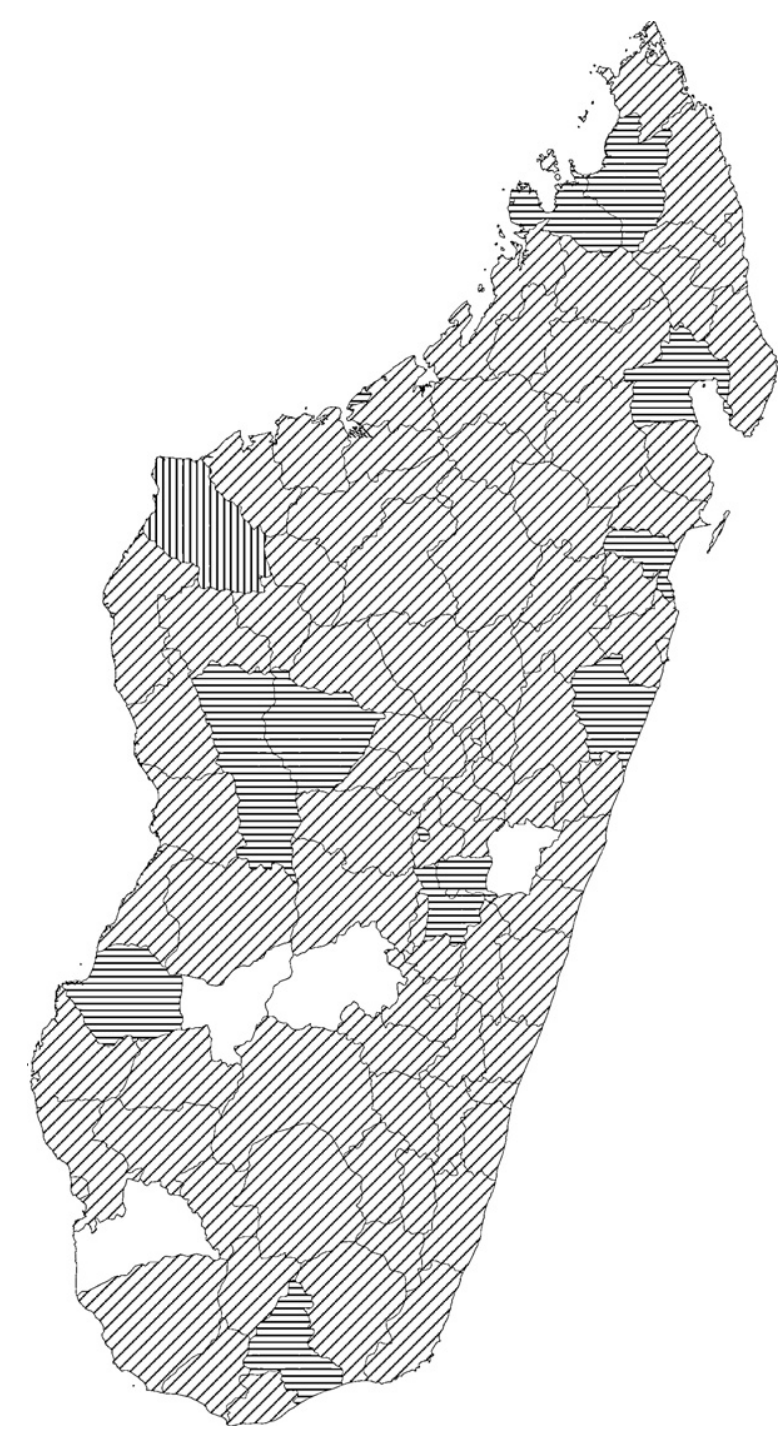

Fig. 1. Distribution of Crimean-Congo hemorrhagic fever (CCHF) in the 111 administrative districts from Madagascar, 2008 and 2009. Antibody data for immunoglobulin (Ig) levels against CCHF virus in serum samples from at-risks professionals are indicated with dark verticals (IgM positive and IgG negative), with dark horizontals (IgG positive and IgM negative), with dark upward diagonals (IgG and IgM negative). No sample was received from districts shown in white.

circulations of CCHFV within the country. For Rift Valley fever, we have genetic evidence that outbreaks in Madagascar resulted from multiple virus introductions from the east Africa mainland rather than enzootic maintenance. ${ }^{10}$ Livestock movements were already implicated in the large diffusion of RVFV during the 2008-2009 outbreak. ${ }^{6}$

Since the first investigations carried out by the Institut Pasteur in the 1970s, 16 arboviruses or related viruses have been isolated in Madagascar. ${ }^{9,11-13}$ CCHFV is the only member of the genus Nairovirus detected in the island. However, we cannot exclude the presence of an undected nairovirus close to CCHFV like viruses from the Nairobi sheep disease group including the eponym virus and Dugbe virus, present and widespread in continental Africa (http://www.cdc.gov/nczved/divisions/dvbid/arbovirus.html). Consequently, the occurrence of cross-reaction in our detection of antibodies against CCHFV, if any, highlights the very low circulation of CCHFV in Madagascar. 
An assessment of the prevalence in livestock as a sensitive indicator of CCHFV activity must be considered in order to confirm the lack or the weak endemicity of CCHF in Madagascar.

\section{Funding}

This work was funded by Institut Pasteur de Madagascar.

\section{Competing interests}

There is no conflict of interest and absence of any relationship or any degree of conflicting or dual interest, financial or of any other nature that may affect professional judgment in relation to this article.

\section{Ethical approval}

Ethical Approval was given by the "Comité National d' Ethique" of Madagascar. Judgement's reference number: O22-CE/MINSAN.

\section{Acknowledgments}

We thank health care officers at Ministry of Public Health of Madagascar for their assistance in collecting the data and samples of patients.

\section{References}

1. Whitehouse CA. Crimean-Congo hemorrhagic fever. Antiviral Res 2004;64:145-60
2. Hoogstraal H. Epidemiology of tick-borne Crimean-Congo hemorrhage fever in Asia, Europe, and Africa. J Med Entomol 1979;15:307-417.

3. Mathiot CC, Fontenille D, Digoutte JP, Coulanges P. First isolation of CongoCrimean haemorrhagic fever virus in Madagascar. Ann Inst Pasteur Virol 1988;139:239-41.

4. Rodriguez LL, Maupin GO, Ksiazek TG, Rollin PE, Khan AS, Schwarz TF, et al. Molecular investigation of a multisource outbreak of Crimean-Congo hemorrhagic fever in the United Arab Emirates. Am J Trop Med Hyg 1997;57: 512-8.

5. Mathiot CC, Fontenille D, Georges AJ, Coulanges P. Antibodies to haemorrhagic fever viruses in Madagascar populations. Trans $R$ Soc Trop Med Hyg 1989;83:407-9.

6. Andriamandimby SF, Randrianarivo-Solofoniaina AE, Jeanmaire EM, Ravololomanana L, Razafimanantsoa LT, Rakotojoelinandrasana T, et al. Rift Valley fever during rainy seasons, Madagascar, 2008 and 2009. Emerg Infect Dis 2010;16:963-70.

7. Khan AS, Maupin GO, Rollin PE, Noor AM, Shurie HH, Shalabi AG, et al. An outbreak of Crimean-Congo hemorrhagic fever in the United Arab Emirates, 1994-1995. Am J Trop Med Hyg 1997;57:519-25.

8. Nabeth P, Cheikh DO, Lo B, Faye O, Vall IO, Niang M, et al. CrimeanCongo hemorrhagic fever, Mauritania. Emerg Infect Dis 2004;10: 2143-9.

9. Fontenille D. Arbovirus transmission cycles in Madagascar. Arch Inst Pasteur Madagascar 1989;55:1-317 [in French].

10. Carroll SA, Reynes JM, Khristova ML, Andriamandimby SF, Rollin PE, Nicho ST. Genetic evidence for Rift Valley Fever outbreaks in Madagascar resulting from virus introductions from the East African mainland rather than enzootic maintenance. J Virol 2011 Jul;85(13):6162-7.

11. Rousset D, Randriamparany $T$, Maharavo Rahantamalala $C Y$, Randriamahefa $\mathrm{N}$, Zeller H, Rakoto-Andrianarivelo M, et al. African Swine Fever introduction into Madagascar, history and lessons from an emergence. Arch Inst Pasteur Madagascar 2001;67:31-3.

12. Ratsitorahina M, Harisoa J, Ratovonjato J, Biacabe S, Reynes JM, Zeller H, et al Outbreak of dengue and Chikungunya fevers, Toamasina Madagascar, 2006 Emerg Infect Dis 2008;14:1135-7.

13. Razafindratsimandresy R, Jeanmaire EM, Counor D, Vasconcelos PF, Sall AA, Reynes JM. Partial molecular characterization of alphaherpesviruses isolated from tropical bats. J Gen Virol 2009;90:44-7. 